This item was submitted to Loughborough's Research Repository by the author.

Items in Figshare are protected by copyright, with all rights reserved, unless otherwise indicated.

\title{
Pregnant driver injury investigations in oblique crashes
}

PLEASE CITE THE PUBLISHED VERSION

http://dx.doi.org/10.1080/13588265.2012.664008

PUBLISHER

(c) Taylor \& Francis

VERSION

AM (Accepted Manuscript)

PUBLISHER STATEMENT

This work is made available according to the conditions of the Creative Commons Attribution-NonCommercialNoDerivatives 4.0 International (CC BY-NC-ND 4.0) licence. Full details of this licence are available at: https://creativecommons.org/licenses/by-nc-nd/4.0/

\section{LICENCE}

CC BY-NC-ND 4.0

\section{REPOSITORY RECORD}

Esat, Volkan, and B. Serpil Acar. 2019. "Pregnant Driver Injury Investigations in Oblique Crashes". figshare. https://hdl.handle.net/2134/25637. 


\title{
Pregnant Driver Injury Investigations in Oblique Crashes
}

\author{
V Esat and B Serpil Acar \\ Department of Computer Science / Research School of Informatics, Loughborough University, LE11 3TU, UK
}

\begin{abstract}
Kinetics and kinematics of an oblique impact are different when compared to frontal collisions. The objective of this research is to simulate various oblique crash scenarios that pregnant drivers may experience by using the computational pregnant occupant model, 'Expecting' and investigate potential injuries that pregnant drivers may suffer. Half-sine acceleration pulses representing crash speeds $15 \mathrm{kph}$ to $45 \mathrm{kph}$ are used in the simulations. Oblique impact simulations are conducted both from the nearside and the farside (offside) of the vehicle. The placental abruption and hence fetus mortality risks during oblique crashes are compared with the full-frontal impact cases.
\end{abstract}

Keywords: pregnant driver, oblique impact, placental abruption, injury criteria

\section{NOTATION}

\author{
$\Delta t \quad$ impact duration of the pulse \\ $\Delta V \quad$ change in velocity \\ ATD Anthropomorphic Test Device \\ UPI Uteroplacental interface
}

\section{INTRODUCTION}

Motor vehicle crashes are statistically the major cause of traumatic injuries for pregnant women and their fetuses [1]. Research shows that the number of pregnant women as vehicle occupants is increasing each year [2]. Women are likely to be vehicle drivers or passengers during their pregnancy and according to the most recent UK statistics, there are approximately 800,000 new maternities each year [3-5]. Various factors such as increased employment by young women also result in an increase in average number of annual vehicle miles driven by women of a reproductive age [6]. In the light of all these facts, investigating road traffic collisions involving pregnant women, focusing on the fetus' and woman's well-being, is an important area of research.

It is not viable to investigate the safety and the risk of injury of pregnant occupants in automobile collisions via cadaver experiments and human volunteer tests due to ethical issues. Real world crash data on pregnant occupant injuries is also scarce. One way of investigating pregnant occupant involvement in automobile accidents is to employ physical models, namely Anthropomorphic Test Devices (ATDs). The Hybrid III small female ATD is integrated with a pregnancy insert in order to convert the dummy into a physical pregnant woman model [7]. The second generation pregnant ATD, 'MAMA2B' has a water filled bladder, equivalent to the size of a 30th week pregnant uterus, and a neoprene 'skin' jacket [8]. No placenta or fetus are included in the model, however pressure in the bladder is measured and used in calculating fetal injury risk.

The other way of effectively investigating pregnant safety in crashes is to use computational human body models, which offer cost-effective and rapid solutions with a greater level of anatomical detail, potentially resulting in an improved biofidelic response over ATDs. The model by Moorcroft et al [9], integrates an FE uterus representing around the $30^{\text {th }}$ week of pregnancy into an existing $5^{\text {th }}$ percentile female occupant. However, the model does not include a fetus.

In this study, the dynamic response of pregnant women during full-frontal and oblique accident simulations are conducted with 'Expecting'. The three dimensional computational model 'Expecting', which includes a detailed multi-body model of a 38-week old fetus in a finite element model of a uterus with a placenta, was developed by Acar and van Lopik at Loughborough University [10].

Previous research reveal that a high percentage, more than 70\%, of all frontal impacts are not fullfrontal collisions; they are predominantly oblique or offset [11-13]. In oblique impact situations, the 
kinetics and kinematics of the occupant differ significantly from the uniaxial impacts, such as the fullfrontal impact. In an oblique impact situation, the components of the acceleration pulse act in two principal directions as longitudinal and lateral, which result in a combined response of the occupant. The design of the 3-point seat belt is also considered to be of vital importance in terms of the impact direction. The shoulder portion passes along the torso diagonally from one shoulder on one side of the occupant towards the hip below on the opposite side. Therefore, the direction of the oblique impact may potentially affect the protection provided by the seat belt. This study aims to shed light on pregnant occupant safety during frontal automotive crashes by investigating oblique impacts and comparing results with those from full-frontal crashes.

\section{METHODOLOGY}

'Expecting', the computational pregnant occupant model, is used to simulate the kinematics of pregnant driver in oblique crashes from both sides of the automobile up to 45 degrees of impact.

\section{The pregnant occupant model: 'Expecting'}

Expecting tackles the complexity of a pregnant woman's anatomy by integrating a detailed multi-body representation of a fetus within a finite element uterus model, both of which are supported with an existing $5^{\text {th }}$ percentile female model modified to incorporate pregnant anthropometry [10]. The model is built in the multi-body/finite-element software package MADYMO. The multi-body fetus model representing 38th week of pregnancy, comprises 15 rigid bodies representing various anatomical regions of the fetus interconnected by kinematic joints with a total fetal mass of $3.3 \mathrm{~kg}$. The overall model sitting in a car interior is shown in Figure 1.

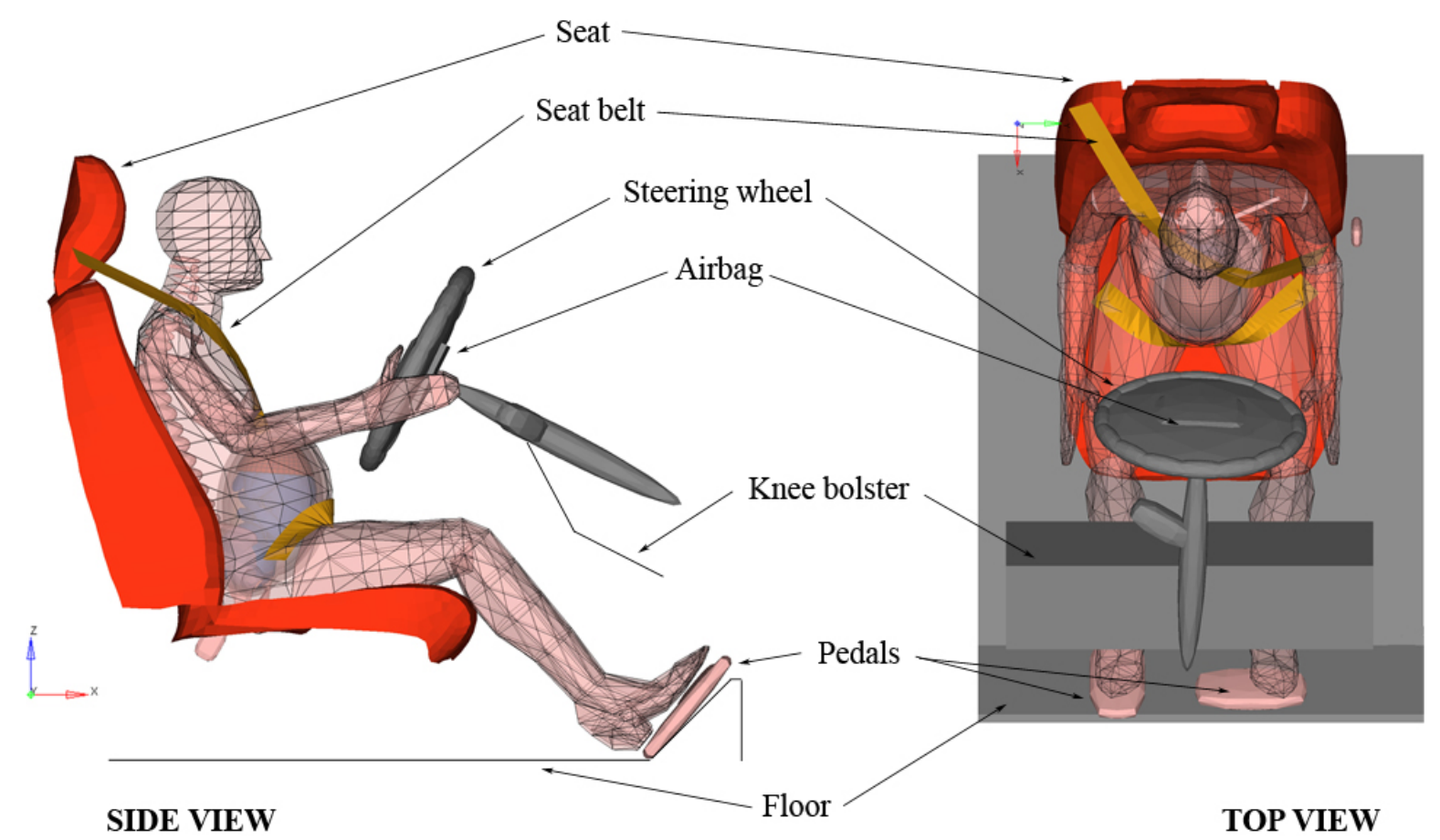

Figure 1. 'Expecting'

The finite element uterus model is developed in conjunction with the multi-body fetus model with the fetal dimensions and configuration controlling the dimensions of the uterus to give a snug fit around the fetus as shown in Figure 2. A layer of fat is meshed around the outer surface of the uterus. The resulting total mass of the uterus with placenta is $1.29 \mathrm{~kg}$. The placenta and uterus in the model 
share a common finite element interface, elements completely connected at nodes, but with different material properties. The pregnant occupant model is validated against rigid-bar impact and belt loading tests [10].

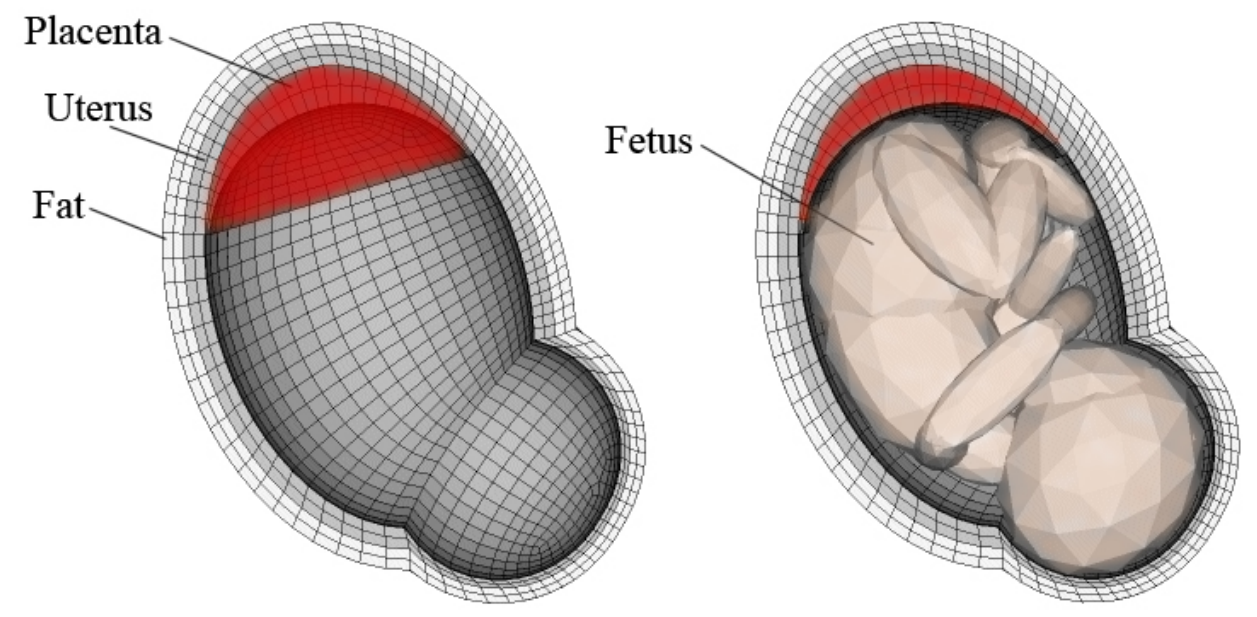

Figure 2. The uterus, placenta and fetus in 'Expecting'

\section{Simulation settings}

Oblique crash simulations are conducted to investigate the response of the pregnant occupant model 'Expecting' as the vehicle driver. The model incorporates a standard 3-point seat belt and a driver's airbag. Any other safety features such as the curtain airbags are not included in the model.

In MADYMO applications, Finite Element (FE) driver airbag model with Computational Fluid Dynamics (CFD) gas flow module is generated for in- and out-of-position simulations [14]. Expecting is based on the in-position $5^{\text {th }}$ percentile pregnant female driver, seated in an optimal seating position with the assumption of making a proper use of the safety seat belt. The airbag is folded and placed in a box at the centre of the steering wheel. It is meshed with linear triangular 3-node membrane (MEM3) elements, which do not possess hourglass modes and potentially describe the geometry of the components better. The element strains and stresses are calculated with the GREEN formulation in order to handle large deformations [14].

Four groups of simulations are conducted and compared with the previously simulated full-frontal impact case [10]; oblique impacts from the nearside of the vehicle with impact angles of $30^{\circ}$ and $45^{\circ}$, and oblique impacts from the farside (offside) of the vehicle with impact angles of $30^{\circ}$ and $45^{\circ}$, as illustrated in Figure 3. Nearside is defined as the passenger side and farside (offside) is the driver side.
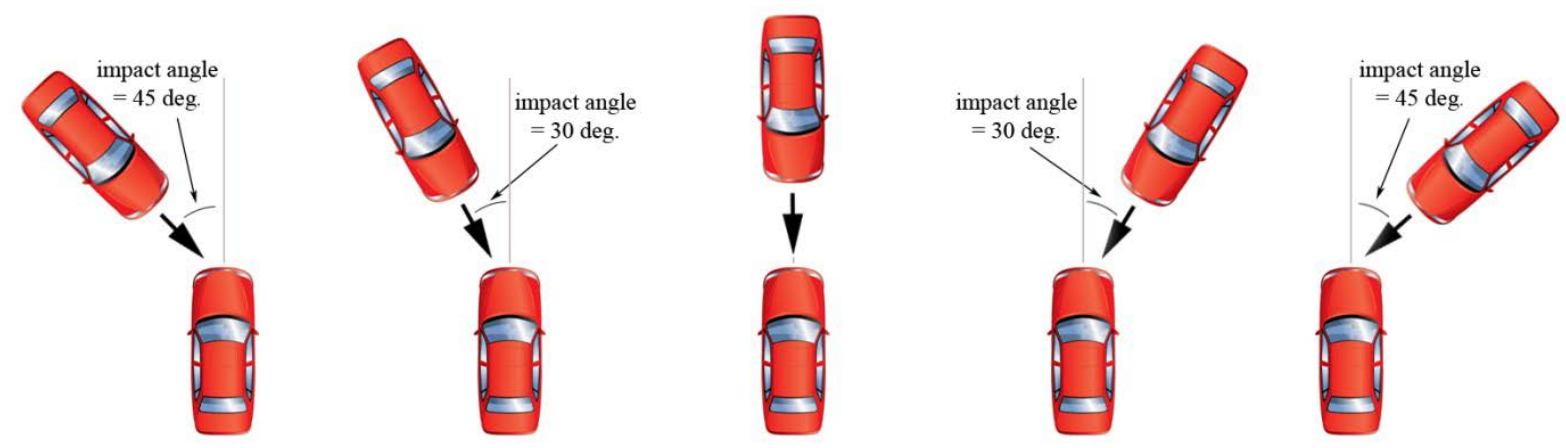

Figure 3. Impact directions and angles 
For each group, simulations are run with crash speeds of $15 \mathrm{kph}$ to $45 \mathrm{kph}$ with $5 \mathrm{kph}$ increments. Half-sine wave acceleration pulses with 120 ms duration are applied to the model as depicted in Figure 4.

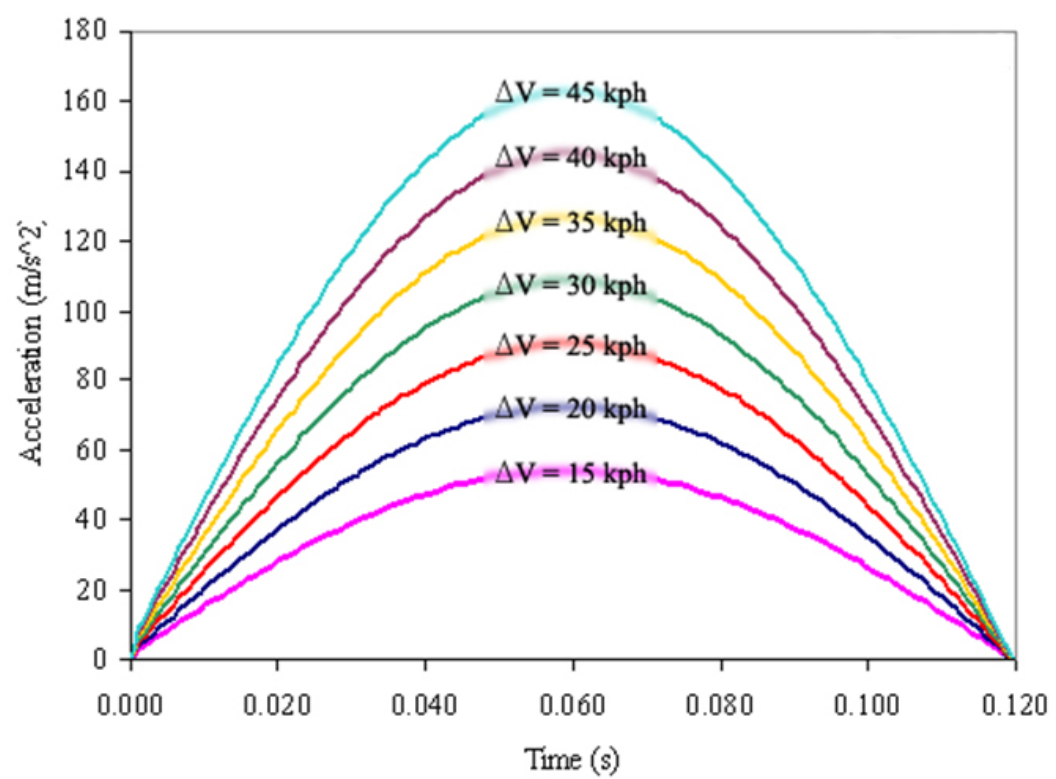

Figure 4. Half-sine acceleration pulses used as input for the crash simulations.

\section{Injury criterion}

Maximum von Mises equivalent strain levels in uterus at placental location and in overall uterus are collected from the model simulations to predict the placental abruption, which leads to fetal and occasionally maternal death. The threshold strain value for the occurrence of placental abruption is widely accepted to be 0.60 at the UPI [8].

\section{RESULTS}

Maximum strains at UPI (Utero-Placental Interface), maximum overall strains in uterus and are computed to investigate the risk to the fetus. The results are illustrated for the four groups of oblique impact cases, and compared with the full-frontal impact predictions. Figure 5 depicts typical simulation results for all five cases showing the model kinematics from front, side and top views; all for $35 \mathrm{kph}$ impact velocity at $100 \mathrm{~ms}$ of impact instant.

Maximum von Mises strains occurring in uterus at placental location, namely at the uteroplacental interface (UPI), and maximum von Mises strains anywhere in the uterus are presented in Figures 6 and 7 for all cases respectively. Any values above 0.60 indicate serious risk of placental abruption potentially leading to fetal death. Figure 6 shows a similar trend, increasing from $15 \mathrm{kph}$ to $45 \mathrm{kph}$ for all cases.

Full-Frontal Impact and Oblique-farside $30^{\circ}$ Impacts result in strains below 0.60 threshold for all impact severities considered. Oblique-farside $45^{\circ}$ and Oblique-Nearside $30^{\circ}$ demonstrate a similar behavior, strain levels reaching 0.60 at $30 \mathrm{kph} \Delta V$. Oblique-Nearside $45^{\circ}$ shows a very sharp rise in strain level at and beyond 35kph $\Delta V$.

Maximum Von Mises strains anywhere in the uterus show similar behavior to the UPI strains but generally with higher strain levels. 

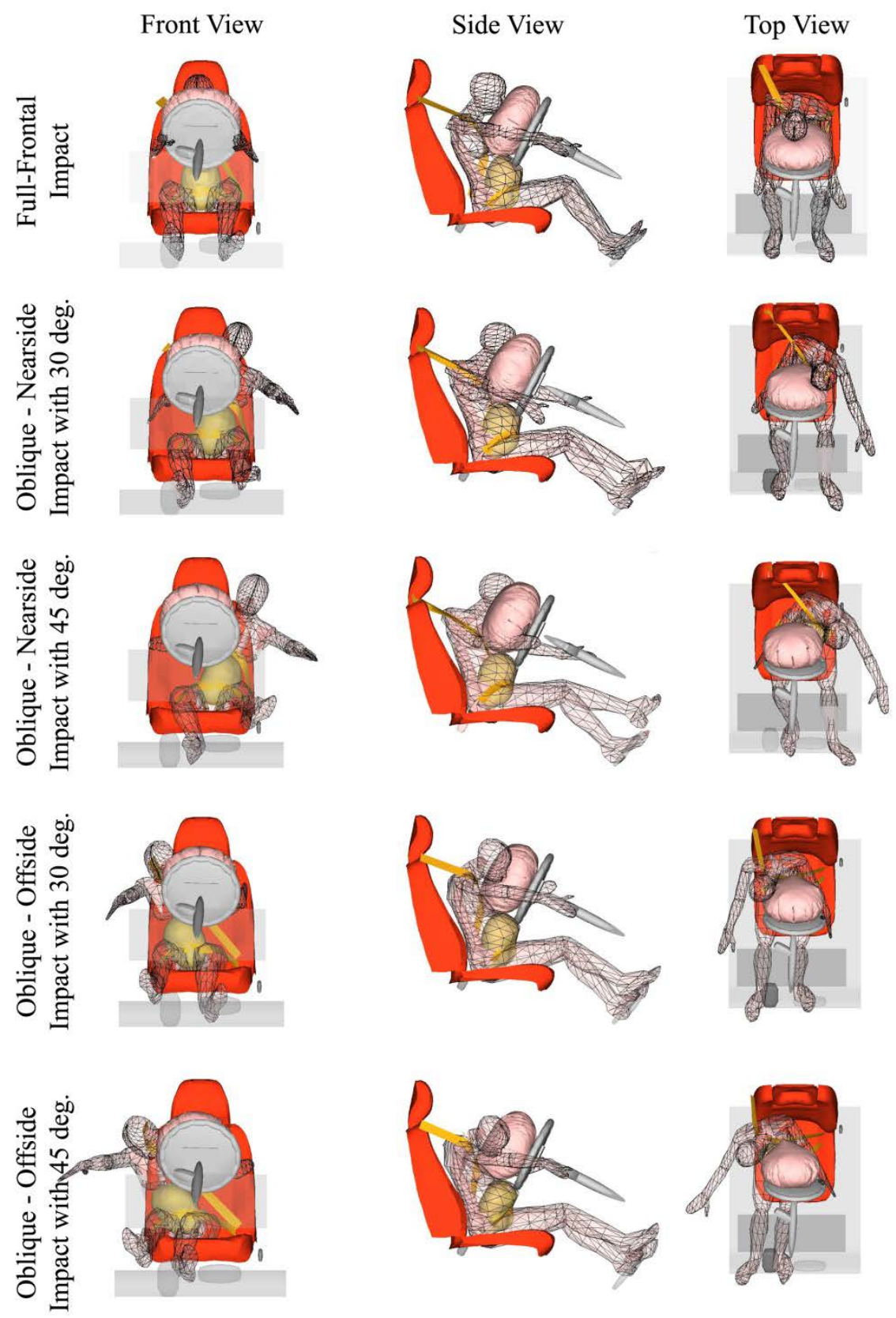

Figure 5. Views from accident simulations for $35 \mathrm{kph}$ crash at $100 \mathrm{~ms}$ of impact 


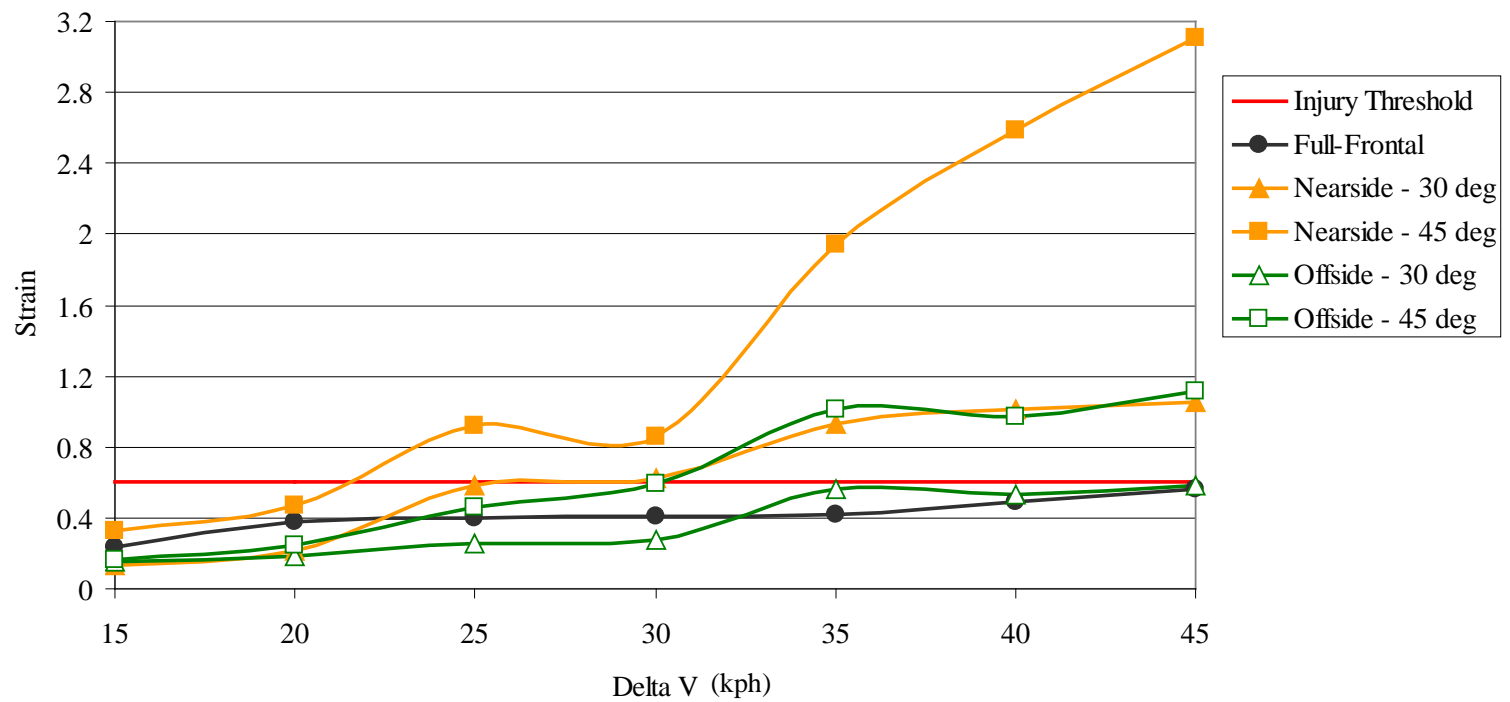

Figure 6. Maximum von Mises strains at the uteroplacental interface (UPI) vs $\Delta V$ (kph)

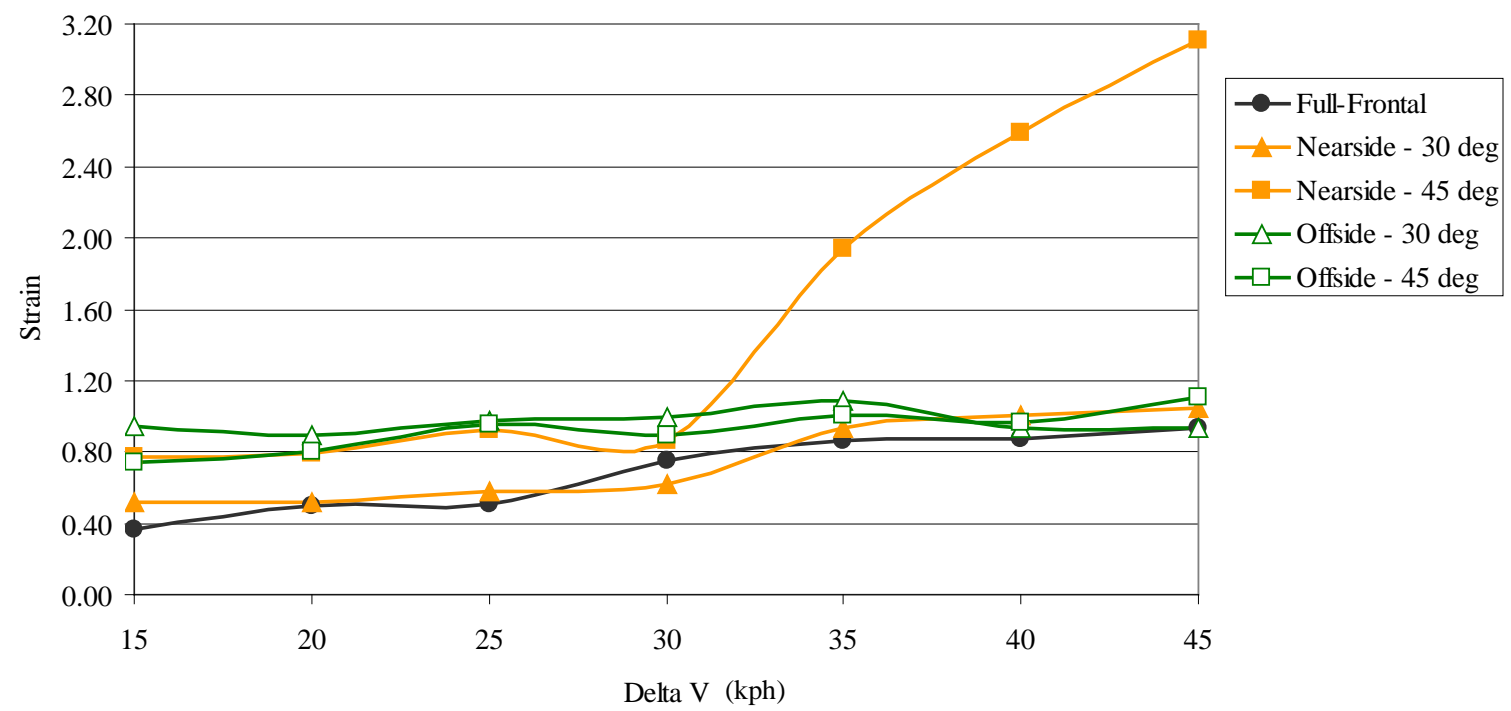

Figure 7. Maximum von Mises strains in overall uterus vs $\Delta V(\mathrm{kph})$

\section{DISCUSSION AND CONCLUSIONS}

The computational model 'Expecting' which also incorporates a fetus is shown to be a useful tool in the investigations of pregnant drivers' safety in oblique crashes. The simulations have provided an insight into a wider range of impact scenarios in addition to full-frontal collisions.

The results demonstrate that oblique impacts cause generally higher strain levels in the uterus when compared with the full frontal impacts. Oblique-Nearside $30^{\circ}$ values yield results very similar to those of Oblique-farside $45^{\circ}$ impact. Oblique-Nearside crashes cause greater strain levels than Oblique- 
farside crashes. This is attributed to the 3-point seat belt configuration. As the seat belt system is not symmetric; it therefore affects the pregnant driver's response differently against impacts coming from different directions. The shoulder portion of the 3-point seat belt for the driver runs from the farside shoulder towards the nearside hip below. During a Nearside impact, the torso of the driver is not restrained by the shoulder belt and moves relatively freely out of the shoulder portion, whereas during an farside impact, the shoulder portion restrains the torso from further displacement towards vehicle interior as seen in Figure 5. In Nearside crashes the lower portion of the shoulder belt exerts pressure on the abdomen, in turn giving rise to strain levels. A combination of the lap belt restriction and the lack of shoulder belt restriction, and the compression between the torso and the thighs, cause the fetus move more freely and at the same time is forced towards the placenta. This movement of the fetus during impact explains very high strain values at the utero-placental interface (UPI) for both Nearside cases.

It should be noted that there is no widely accepted injury criteria for the overall strains in uterus, unlike the commonly accepted injury threshold of 0.60 for the strains in UPI region in uterus. In general high strains are not desirable in any part of the uterus, which may eventually cause tears, bleeding or discomfort.

In the oblique impact cases investigated in this study, steering wheel loading appears to be minimal whereas in full-frontal impacts, the risk associated with the placental abruption is mostly due to steering wheel loading on uterus at the UPI.

This research suggests that during oblique crashes, the strain values at the placental location of the uterus are greater than the threshold value for placental abruption especially at higher speed collisions and collisions with large oblique impact angles. Oblique Nearside crashes appear to be more hazardous than Oblique farside crashes for the fetus.

\section{ACKNOWLEDGEMENTS}

The authors gratefully acknowledge funding support from EPSRC and IMCRC (Innovative Manufacturing and Construction Research Centre) of Loughborough University. The authors also thank MADYMO.

\section{REFERENCES}

1 M D Pearlman, 'Motor vehicle crashes, pregnancy loss, and preterm labor', International Journal of Gynecology \& Obstetrics, 199757 (2) 127-132.

2 P Haapaniemi, 'Women’s highway deaths on the rise’, Traffic Safety, 1996 96 6-11.

3 Office for National Statistics, Birth Statistics - Review of the Registrar General on births and patterns of family building in England and Wales, Series FM1, No. 35, 2009.

4 The Scottish Government, Births in Scotland - High Level Summary of Statistics Trend. GROS Registration Data, Statistics, 2009.

5 NISRA, Statistics Press Notice - Births in Northern Ireland, 2009.

$6 \mathrm{H}$ B Weiss, 'Hidden epidemic of maternal, fetal, and neonatal mortality and injury from crashes - A case of societal neglect?', Transportation Research Record: Journal of the Transportation Research Board, 2006 (1956) 133-140.

7 M D Pearlman and D Viano, 'Automobile crash simulation with the first pregnant crash test dummy', Am J Obstet Gynec, 1996175 977-981.

8 J D Rupp, K D Klinich, S Moss, L Zhou, M D Pearlman, and L W Schneider, 'Development and testing of a prototype pregnant abdomen for the small female Hybrid III small female ATD’, Stapp Car Crash Journal, 200145 61-78.

9 D Moorcroft, S Duma, J Stitzel and G Duma, 'A finite element and multi-body model of the pregnant female occupant for the analysis of restraint effectiveness', SAE Transactions, 2003-01-0157, 2003112 (6) 62-70.

10 B S Acar and D van Lopik, 'Computational pregnant occupant model, 'Expecting', for crash simulations', Proc. IMechE Part D: J. Automobile Engineering, 2009223 891-902.

11 F Hartmann and C Tarriere 'Synthesis of Statistical Data on Traffic Accidents in France, West Germany, Italy and the United Kingdom’, Proc. 5th International Technical Conference on the Enhanced Safety of Vehicles, 1974 405-413. 
12 D Scheunert, R Justen, R Herrmann, F Zeidler, J Decker and I Kallina, 'What Is a Realistic Frontal Offset Test Procedure?’, Proc. International IRCOBI Conference on the Biomechanics of Impact, 1992 75-87.

13 C Ragland, O Fessahaie and D Elliott, 'Evaluation of Frontal Offset/Oblique Crash Test Conditions’, Proc. 17th International Technical Conference on the Enhanced Safety of Vehicles, Paper No. 3852001.

14 MADYMO Theory Manual, Airbag Models, TNO MADYMO BV, 2007 253-296. 